\title{
PLANING AND CONSTRUCTING GAS MAINS USING GPR
}

\author{
Dipl.-Geophysiker Hartmut Weitzel \\ Georadar GmbH, Riessnerstrasse 20, D-99427 Weimar
}

\section{The SITUATION}

In general gas pipes are planned and constructed under strong economical conditions. The more information you get in front of a project the more the economy will increase. According to innovative technologies the planning has become different and more demanding. The systems to construct a pipeline, especially trenchless technologies need more information of the subsurface in the stage of planning. Geophysical methods are in the planning departments almost unknown or unusual. In the last 10 years an increase in the use of geophysical methods for inspecting pipe-traces is seen. The most powerful instrument for subsurface inspection in the upper $5 \mathrm{~m}$ is the GPR-technology.

\section{THE METHOD}

In the late 80's GPR was adapted to the requirements of trenchless pipe construction methods. So GPR in combination with geological probing and additional geophysical methods especially for river-, highway- or railroadcrossings gives information about the soil, soilconditions, soilvariations and some soilparameters as e. g. humidity or clay contend. Further you get information about existing pipes and cables as well as different objects and subsurface constructions. 3d-interpretation methods allow spatial structures to be visualized and give maximum information of the expected pipe trace.

GPR is used with frequencies of $100 \mathrm{MHz}$ to $1.000 \mathrm{MHz}$ to show up base structures, soil variations and small structures. The combination of GPR-sensors is chosen according to the specific job. At least two parallel profiles along the trace have to be measured to suggest the interpretation of the detected anomalies. Cross profiles are the first step to have a spatial view into the ground.

\section{FLOW OF A PROJECT}

The first contact with e. g. a gas acompany takes place in phase 1 of a gas main construction, where the number of households that want to get a gas-connection is found. The first job for GPR is to check the existing subsurface infrastructure and give an idea where the pipe can be constructed. Next step is to show up the soil conditions and check the possibilities of trenchless construction methods. In front of the construction companies the existing pipes and cables as well as subsurface objects in the planned trace have to be extracted out of the GPR data. The resulting plan shows e. g. the possible drilling path or construction horizon. 


\section{RESULTS}

GPR is a cost effective and powerful tool to inspect proposed pipe traces. Measuring profiles in $\mathrm{x}$ - and $\mathrm{y}$-direction and interpreting the different events in the radar data like reflectivity, absorption and frequency dispersion gives a 3 dimensional view of the subsurface. In combination with drillings all parameters for trenchless construction are available. The figures show a radar data set along the profile line and an other perpendicular to that line. In the alongside profile different soil conditions from anthropogen filling material to weathered rock and solid rock are presented. The perpendicular line locates the pipes which are alongside the planned pipe trace. A 3D-imaging of the underground is reached.

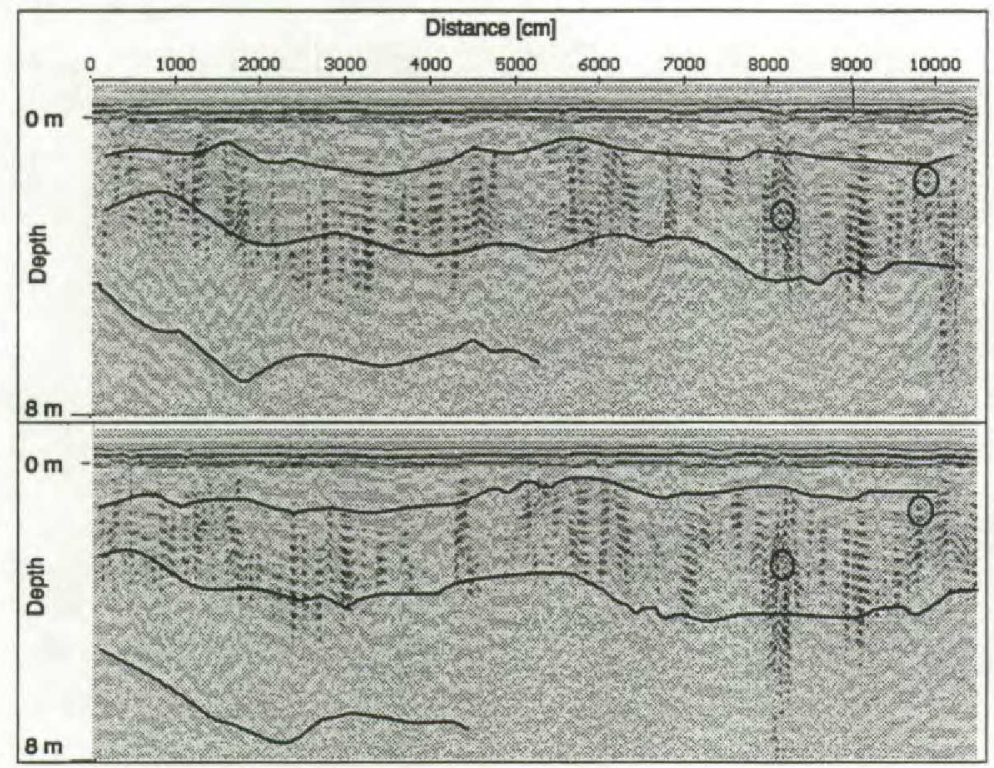

Radar section alongside a planned pipe trace showing different soil conditions

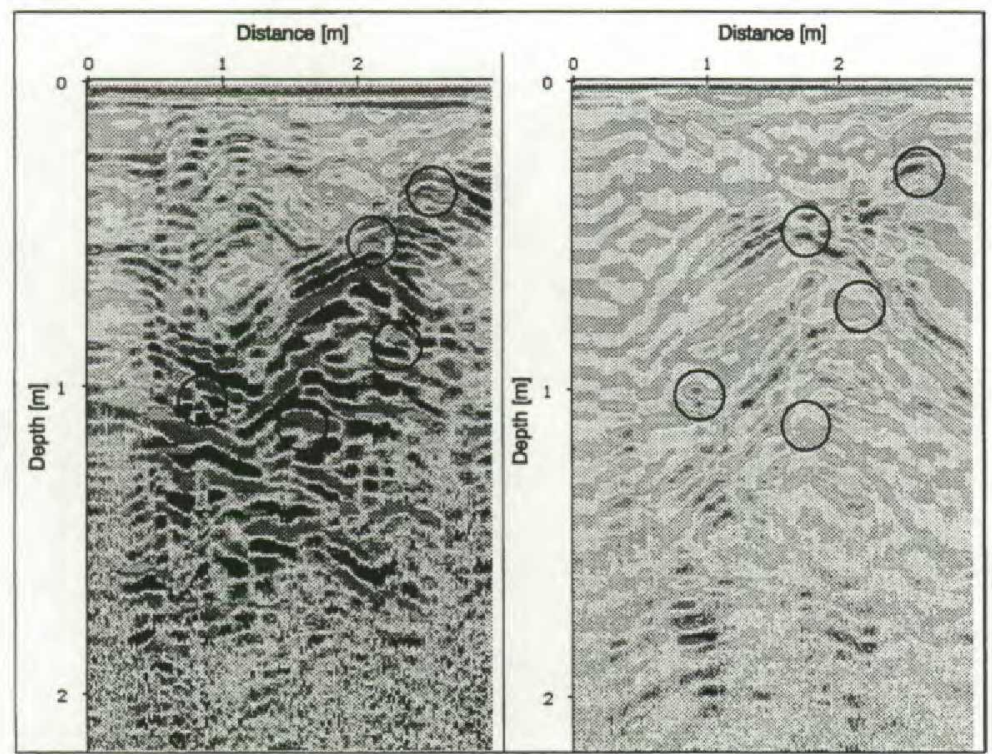

Cross section showing pipe anomalies 
Interpretation of the radar data is the essential skill which needs experienced operators.

The interpreted results will be transformed in a plan which the staff of gas company can work with.

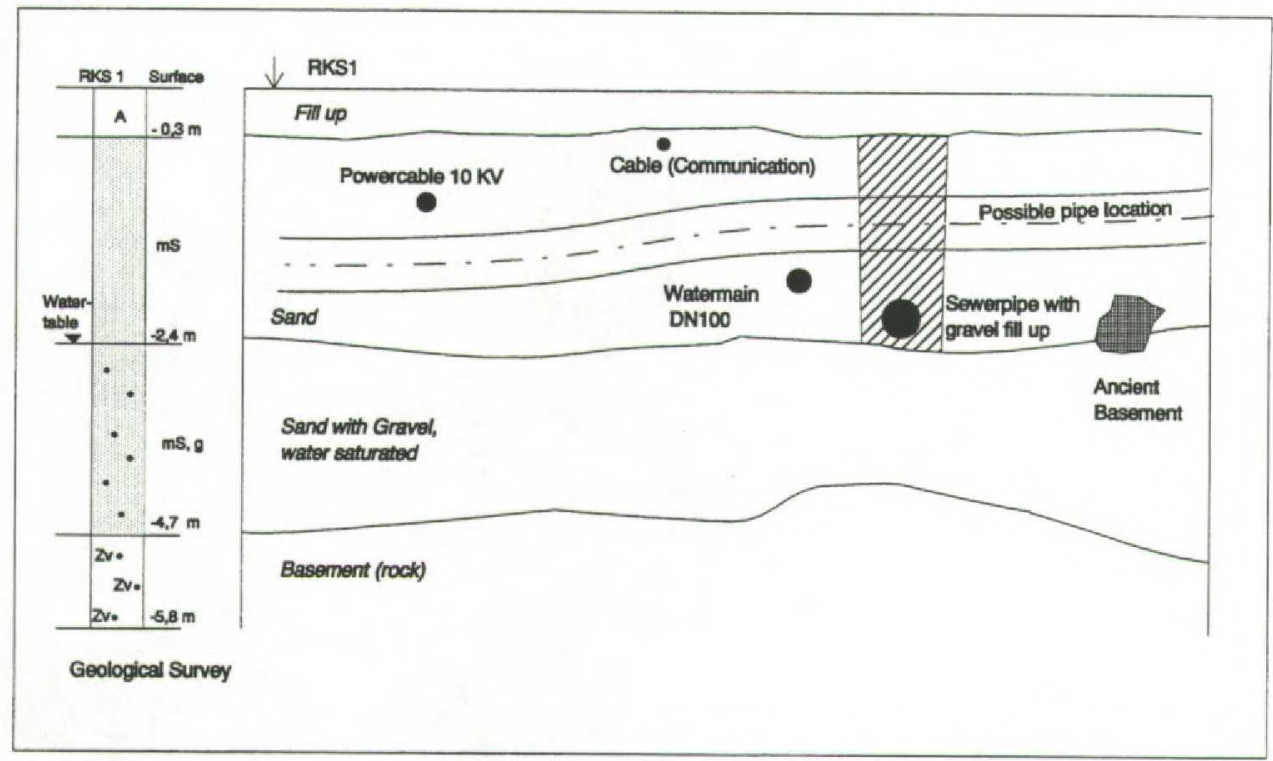

Longitudinal section of a GPR profile with interpretation and proposed pipe location.

According to the survey results the planned pipe trace can be devided in parts with trenchless construction method or the conventional one. Determined planning of the constructions process is possible. 
